EESTI NSV TEADUSTE АKADEEMIA TOIMETISED 1954. III kd., nr. 3
ИЗВЕСТИЯ АКАДЕМИИ НАУК ЭСТОНСКОИ ССР 1954. Том III, № 3

\title{
О СОСТАВЕ ГАЗА ПРОМЫШЛЕННОГО ПОЛУКОКСОВАНИЯ СЛАНЦА-КУКЕРСИТА
}

\author{
А. т. КЫЛль, \\ кандидат химических наук \\ И. И. СТЕПАНОВ, \\ кандидат технических наук
}

Директивы XIX съезда КПСС ставят большие и ответственные задачи перед газовой промышленностью Советского Союза. В директивах предусматривается «увеличить за пятилетие, примерно, на 80 процентов добычу природного газа и попутного нефтяного газа, а также производство газа из угля и сланцев. Расширить использование газа для бытовых нужд, применение его в качестве автомобильного топлива и получение из газа химических продуктов».

Известно, что газ является неизбежным продуктом термической переработки горючего сланца по любой схеме.

Эксплуатация камерных печей и шахтных генераторов производится с целью переработки горючего сланца в основном на бытовой и энергетический газ.

Единственной задачей туннельных печей является получение искусственного жидкого топлива переработкой сланцев. Получающийся при этом газ (с выходом 3,5-4,5\% от веса исходного сланца) используется только для отопления самих туннельных печей.

Несмотря на то, что в газе туннельных печей содержится большое количество химически ценных углеводородов непредельного ряда ( $\left.{ }^{5}\right)$, его состав до сих пор оставался недостаточно изученным.

С развитием в Әстонии газовой промышленности встал вопрос о тщательном исследовании состава сланцевого газа, получаемого при всех системах переработки. Последнее необходимо не только для усовершенствования существующих технологических методов, но и для нужд развнвающейся новой технологии переработки сланцев.

Как известно, за последнее десятилетие химическая промышленность на основе природных, нефтяных и коксовых газов сделала большие успехи в области синтеза высокооктановых бензинов, синтетического каучука, спиртов и т. д. Промышленность органического синтеза освоила производство многих синтетических продуктов на основе переработки газов.

Выбор направления переработки газов определяется многими обстоятельствами, из которых нанболее важным является качество исходного сырья, т. е. состав газовой смеси. В случае природного газа, богатого 
метаном и этаном, переработка ведется с целью получения этилена, ацетилена или синтез-газа. Процессы алкилирования и полимеризации, связанные с потреблением больших количеств бутан-бутиленовых, пропанпропиленовых и других газовых смесей непредельного характера, рациональнее применять к газам пиролиза нефти или твердого топлива.

\section{Общая характеристика газа промышленного полукоксования сланца}

Туннельные печи и вращающиеся реторты являются агрегатами для получения сланцевого жидкого топлива, в которых горючий сланец подвергается постепенному нагреву до 450 или $500^{\circ}$. Несмотря на сходные температурные режимы, технологическое оформление процессов в этих агрегатах различно. В туннельной печи циркулирующая парогазовая смесь многократно проходит через перепреватели, где температура значительно выше, чем в туннеле. При переработке сланца во вращающихся ретортах образующаяся парогазовая смесь быстро эвакуируется из горячей зоны. Однако в обоих случаях газ содержит кислые части в виде $\mathrm{CO}_{2}+\mathrm{H}_{2} \mathrm{~S}$, как продукт начальной стадии разложения сланца, а также в значительных количествах углеводородную часть - продукт более глубокого разложения органической части сланца.

Известно, что при термическом разложении горючего сланца уже при температуре около $250^{\circ}$ начинается интенсивное выделение кислых компонентов $\mathrm{CO}_{2}+\mathrm{H}_{2} \mathrm{~S}(2,3,4)$. Пробы газа, взятые из туннельной печи в начале туннеля, где температура еще не успела подняться выше $250^{\circ}$, характеризуются приблизительно 50-процентной концентрацией суммы $\mathrm{CO}_{2}+\mathrm{H}_{2} \mathrm{~S}$ в газе (по объему). На долю $\mathrm{H}_{2} \mathrm{~S}$ приходится при этом $15-18 \%$.

По мере перехода к концу туннеля и повышения температуры и степени разложения органической части сланца концентрация углеводородных компонентов в газе повышается; в результате относительное содержание $\mathrm{CO}_{2}+\mathrm{H}_{2} \mathrm{~S}$ снижается до $25 \%$; на долю $\mathrm{H}_{2} \mathrm{~S}$ при этом приходится $7-10 \%$.

Таким образом, процесс газообразования в туннельной печи происходит на всем ее протяжении в температурном интервале $250-480^{\circ}$. Подогрев парогазовой смеси в системе калориферов при ее циркуляции также приводит к дополнительному образованию газа. В результате термического разложения сланца полукоксовый сланцевый газ обогащается также неуглеводородными компонентами $\left(\mathrm{H}_{2}\right.$ и $\left.\mathrm{CO}\right)$. Однако доля их невелика и составляет вместе (по объему) около $10 \%$ (табл. 1 и 2). Последний факт свидетельствует об умеренном температурном режиме полукоксования в условиях туннельной печи.

Итак, основными компонентами газа полукоксования кукерсита яв ляются $\mathrm{CO}_{2}+\mathrm{H}_{2} \mathrm{~S}$ и углеводороды предельного характера; последние составляют около $30-35 \%$ от суммарной газовой смеси.

Средний состав газа на основании многочисленных технических анализов по обеим установкам приведен в табл. 1.

Из-за подсосов воздуха в состав газа включаются значительные количества азота. За счет же органического вещества сланца концентрация азота в газе не может быть выше $0,3-0,5 \%$. Проникаюший в туннельную печь и в конденсационную систему кислород воздуха реагирует с продуктами полукоксования.

Из данных табл. 1 видно, что по своему составу газовые омеси прннципиально не отличаются друг от друга, за исключением величины подсо- 
Средний состав сланцевого полукоксового газа

(по данным технического анализа)

\begin{tabular}{|c|c|c|c|c|c|c|c|c|c|}
\hline \multirow{2}{*}{$\begin{array}{c}\text { Наименование } \\
\text { установки }\end{array}$} & \multirow{2}{*}{$\begin{array}{l}\text { Tемпера- } \\
\text { тура } \\
\text { перера- } \\
\text { ботки }{ }^{\circ} \mathrm{C}\end{array}$} & \multicolumn{8}{|c|}{ Содержание компонентов в газе в \% (по объему) } \\
\hline & & $\mathrm{CO}_{2}$ & $\mathrm{H}_{2} \mathrm{~S}$ & $\mathrm{C}_{\mathrm{n}} \mathrm{H}_{\mathrm{m}}$ & $\mathrm{O}_{2}$ & $\mathrm{CO}$ & $\mathrm{H}_{2}$ & $\mathrm{C}_{\mathrm{n}} \mathrm{H}_{2 \mathrm{n}+2}$ & $\mathrm{~N}_{2}$ \\
\hline $\begin{array}{l}\text { Туннельные } \\
\text { печи }\end{array}$ & $450-480$ & $18-25$ & $7-10$ & $20-12$ & $1-2$ & 56 & $4-5$ & $25-30$ & $20-25$ \\
\hline $\begin{array}{c}\text { Вращающиеся } \\
\text { реторты }\end{array}$ & 450 & $15-20$ & $5-8$ & $6-8$ & $3-5$ & $4-5$ & $4-5$ & $25-20$ & $40-50$ \\
\hline
\end{tabular}

сов воздуха и содержания углеводородных компонентов. В газе вращающейся реторты концентрация углеводородов ниже, чем в туннельной печи.

Данные технического анализа, однако, не позволяют судить о характере углеводородной части, так как-компоненты $\mathrm{C}_{\mathrm{n}} \mathrm{H}_{\mathrm{m}}$ и $\mathrm{C}_{\mathrm{n}} \mathrm{H}_{2 \mathrm{n}+2}$ дают представление лишь о суммарном содержании олефиновых или парафиновых углеводородов.

Наличие в газе некоторого количества паров газового бензина влечет за собой при проведении технического анализа некоторое завышение данных по содержанию олефинов. Из данных технического анализа не видно, какой углеводородный компонент газа является преобладающим. В настоящей работе анализ газа осуществлялся методом низкотемпературной ректификации $\left({ }^{1}\right)$. Из газа предварительно удалялись кислые компоненты $\left(\mathrm{CO}_{2}\right.$ и $\left.\mathrm{H}_{2} \mathrm{~S}\right)$ и производилась осушка его. Далее, газ подавался на конденсацию в ректификационный кубик, охлаждаемый жидким воздухом. Ректификация проводилась в спиральной колонке эффективностью в $10-12$ теоретических тарелок.

Схема аппарата позволила разделить газ на фракции $\mathrm{C}_{2}, \mathrm{C}_{3}$ и $\mathrm{C}_{4}$, а также на неконденсирующуюся при температуре жидкого воздуха смесь $\mathrm{CO}, \mathrm{H}_{2}, \mathrm{CH}_{4}$ и $\mathrm{N}_{2}$. Эта смесь анализировалась обычными газоаналитическими методами.

\section{Результаты исследования углеводородной части сланцевого газа}

В табл. 2 и 3 приведены средние составы полукоксового газа, определенные на основании результатов глубокого охлаждения и низкотемпературной ректификации.

Из таблиц видно, что углеводородная часть составляет в газе туннельных печей до $35 \%$; при исключении же подсосов воздуха, ее концентращия может достигать $45 \%$. Содержание ее в газе вращающихся реторт несколько ниже.

Предельные углеводороды распределяются в газовой смеси в следующем соотношении (в процентах):

Туннельная печь Вращающаяся реторта

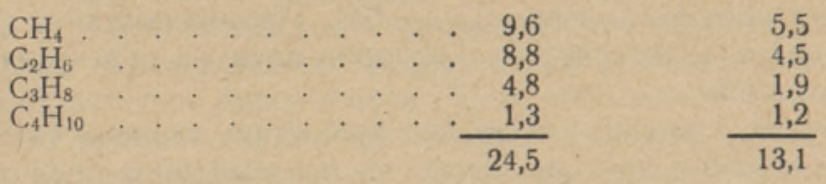


Непредельные углеводороды распределяются в газе в следующем соотношении (в процентах):

Туннельная печь Вращающаяся реторта

$\mathrm{C}_{2} \mathrm{H}_{4}$
$\mathrm{C}_{3} \mathrm{H}_{6}$
$\mathrm{C}_{4} \mathrm{H}_{8}$$\quad \begin{aligned} & 3,5 \\ & 4,6 \\ & 1\end{aligned}$

Таблица 2

Состав газа туннельных печей и вращающихся реторт

(предельные значения)

\begin{tabular}{l|r|r}
\hline \multirow{2}{*}{ Компоненты } & \multicolumn{2}{|c}{ Содержание в газе (\%) } \\
\cline { 2 - 3 } & $\begin{array}{c}\text { туннельной } \\
\text { печи }\end{array}$ & $\begin{array}{c}\text { вращающейся } \\
\text { реторты }\end{array}$ \\
\hline & & \\
$\mathrm{H}_{2} \mathrm{~S}$ & $7,0-10,0$ & $5,0-8,0$ \\
$\mathrm{CO}_{2}$ & $18,0-25,0$ & $15,0-20,0$ \\
$\mathrm{C}_{2} \mathrm{H}_{4}$ & $3,0-4,5$ & $1,5-2,5$ \\
$\mathrm{C}_{2} \mathrm{H}_{6}$ & $8,0-10,0$ & $3,8-4,8$ \\
$\mathrm{C}_{3} \mathrm{H}_{6}$ & $4,0-5,0$ & $1,9-2,2$ \\
$\mathrm{C}_{3} \mathrm{H}_{8}$ & $4,0-5,0$ & $1,4-2,1$ \\
изо $_{4} \mathrm{C}_{8}$ & $0,2-0,3$ & $0,1-0,2$ \\
$\mathrm{Hopм}_{4} \mathrm{C}_{4} \mathrm{H}_{8}$ & $1,3-1,8$ & $1,0-1,6$ \\
$\mathrm{C}_{4} \mathrm{H}_{10}$ & $1,3-1,8$ & $1,1-1,2$ \\
$\mathrm{CO}$ & $6,0-8,0$ & $3,0-5,0$ \\
$\mathrm{H}_{2}$ & $4,0-6,0$ & $4,5-7,9$ \\
$\mathrm{CH}_{4}$ & $8,0-12,0$ & $4,0-7,5$ \\
$\mathrm{~N}_{2}$ & $20,0-30,0$ & $49,0-52,0$ \\
$\mathrm{O}_{2}$ & $0,8-1,2$ & $2,0-4,0$ \\
$\mathrm{C}_{5}$ и выше & $2,0-3,0$ & $1,5-3,3$ \\
& &
\end{tabular}

Таблица 3

Усредненный состав полукоксового сланцевого газа *

\begin{tabular}{|c|c|c|c|c|c|c|}
\hline \multirow[b]{2}{*}{ Компоненты } & \multicolumn{3}{|c|}{ Газ туннельной печи } & \multicolumn{3}{|c|}{ Газ вращающейся реторты } \\
\hline & $\begin{array}{l}\text { Обычный } \\
\text { состав }\end{array}$ & $\begin{array}{c}\text { За выче- } \\
\text { том } \\
\mathrm{N}_{2}+\mathrm{O}_{2}\end{array}$ & $\begin{array}{l}\text { За выче- } \\
\text { том } \mathrm{CO}_{2} \text {, } \\
\mathrm{H}_{2} \mathrm{~S}, \mathrm{~N}_{2} \\
\text { и } \mathrm{O}_{2}\end{array}$ & $\begin{array}{c}\text { Обычный } \\
\text { состав }\end{array}$ & $\begin{array}{c}\text { За выче- } \\
\text { том } \\
\mathrm{N}_{2}+\mathrm{O}_{2}\end{array}$ & $\begin{array}{c}\text { За выче- } \\
\text { том } \mathrm{CO}_{2} \text {, } \\
\mathrm{H}_{2} \mathrm{~S}, \mathrm{~N}_{2} \\
\text { и } \mathrm{O}_{2}\end{array}$ \\
\hline $\begin{array}{l}\mathrm{CO}_{2}+\mathrm{H}_{2} \mathrm{~S} \\
\mathrm{C}_{2} \mathrm{H}_{4} \\
\mathrm{C}_{2} \mathrm{H}_{6} \\
\mathrm{C}_{8} \mathrm{H}_{6} \\
\mathrm{C}_{3} \mathrm{H}_{8} \\
\text { изо } \mathrm{C}_{4} \mathrm{H}_{8} \\
\mathrm{HOpM}_{4} \mathrm{C}_{4} \mathrm{H}_{8} \\
\mathrm{C}_{4} \mathrm{H}_{10} \\
\mathrm{CO} \\
\mathrm{H}_{2} \\
\mathrm{CH}_{4} \\
\mathrm{~N}_{2} \\
\mathrm{O}_{2} \\
\mathrm{C}_{5}\end{array}$ & $\begin{array}{r}23,6 \\
3,5 \\
8,8 \\
4,6 \\
4,8 \\
0,2 \\
1,6 \\
1,3 \\
7,4 \\
5,6 \\
9,6 \\
25,2 \\
1,2 \\
2,6 \\
\end{array}$ & $\begin{array}{r}32,3 \\
4,8 \\
11,9 \\
6,3 \\
6,5 \\
0,2 \\
2,2 \\
1,8 \\
10,0 \\
7,6 \\
13,0 \\
- \\
3,4 \\
\end{array}$ & $\begin{array}{r}\overline{7,1} \\
17,6 \\
9,3 \\
9,6 \\
0,3 \\
3,2 \\
2,7 \\
14,8 \\
11,2 \\
19,2 \\
\overline{-} \\
\overline{5,0} \\
\end{array}$ & $\begin{array}{r}16,6 \\
1,9 \\
4,5 \\
2,0 \\
1,9 \\
0,1 \\
1,5 \\
1,2 \\
4,2 \\
5,2 \\
5,5 \\
50,0 \\
3,2 \\
2,2 \\
\end{array}$ & $\begin{array}{r}34,8 \\
4,1 \\
9,1 \\
4,3 \\
4,0 \\
0,2 \\
3,2 \\
2,6 \\
10,6 \\
11,1 \\
11,3 \\
- \\
4,7 \\
\end{array}$ & $\begin{array}{r}\overline{-} \\
6,3 \\
13,9 \\
6,6 \\
6,0 \\
0,2 \\
4,9 \\
4,0 \\
16,2 \\
17,0 \\
17,3 \\
- \\
\overline{7,6}\end{array}$ \\
\hline & 100,0 & 100,0 & 100,0 & 100,0 & 100,0 & 100,0 \\
\hline
\end{tabular}

* Средние данные по 10 анализам. 
Более ясную картину распределения углеводородных компонентов в сланцевом газе показывает рис. 1, на котором приведены также сравнительные данные по составу нефтяного крекинг-газа $\left({ }^{7}\right)$. Состав сланцевого газа дан в пересчете, с исключением подсосов воздуха согласно данным табл. 3.

Рис. 1 показывает, что по концентрации углеводородов предельного ряда сланцевый газ напоминает нефтяной газ парофазного крекинга (об-

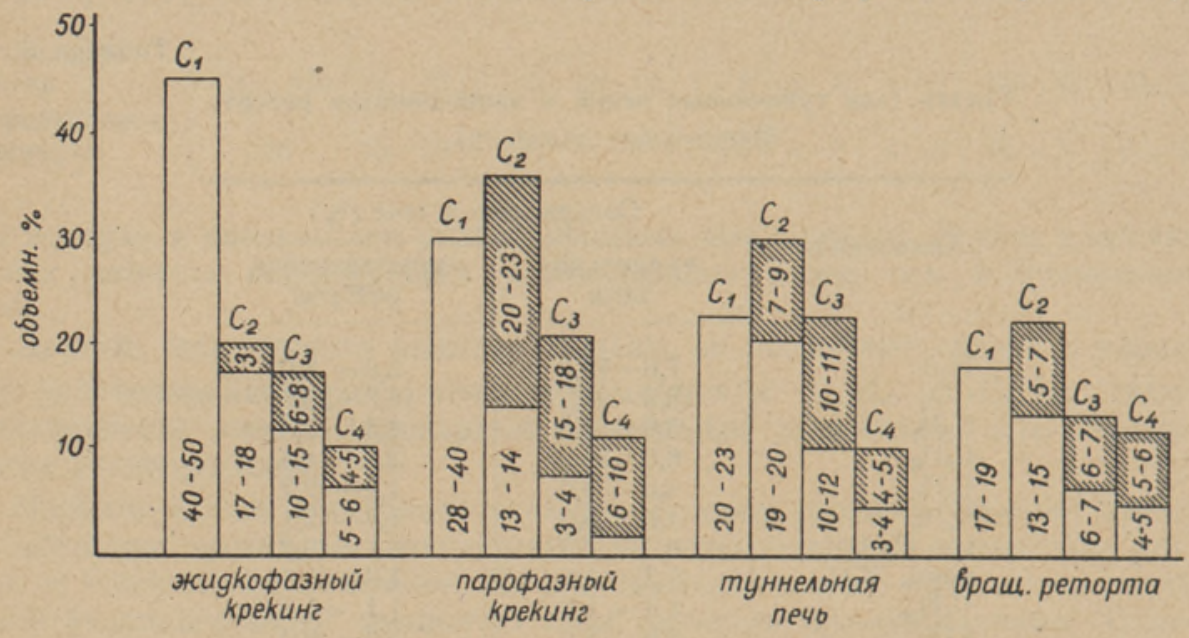

$\square$ преgельные углевоgороgы

непреgельные угебоgородм

Рис. 1.

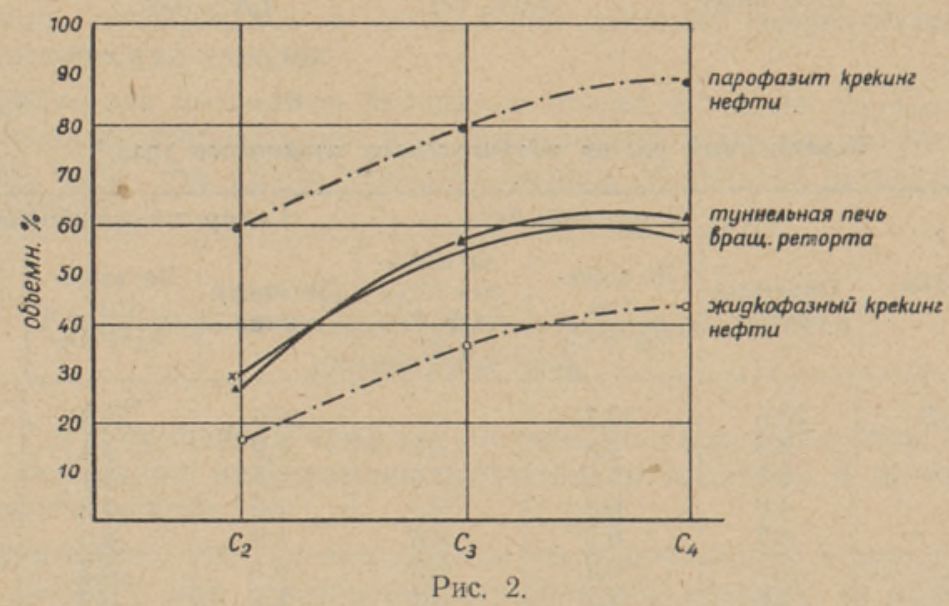

щая концентрация предельных в нефтяном газе $55-57 \%$ и в сланцевом газе $45-50 \%$ ).

По концентрации же углеводородов непредельного ряда сланцевый газ, напротив, несколько приближается к нефтяному газу жидкофазного крекинга, в котором содержание непредельных углеводородов составляет $12-16 \%$; содержание этих компонентов в сланцевом газе достигает $22-24 \%$.

Эту особенность можно видеть также на рис. 2. Кривая степени ненасыщенности углеводородных фракций сланцевого газа проходит между кривыми газов парофазного и жидкофазного крекинга. 
Температурный режим в перегревателях туннельной печи способствует крекингу сланцевой смолы. Однако, как и предусмотрено технологией, этот процесс не заходит далеко, и из всех углеводородных компонентов наибольшую концентрацию имеет фракция $\mathrm{C}_{2}$, при относительно невысоком содержании $\mathrm{C}_{2} \mathrm{H}_{4}$.

Аналогичная картина наблюдается и для полукоксового газа из вращающейся реторты, где условия термического разложения и пиролиза еще более мягкие.

Сланцевый полукоксовый газ содержит больше водорода, чем нефтяной крекинг-газ. Так, в газе парофазного крекинга нефти при $600^{\circ}$ водорода содержится $7-9 \%$ по объему, тогда как в газе туннельных печей (за вычетом балласта $\mathrm{CO}_{2}, \mathrm{H}_{2} \mathrm{~S}, \mathrm{~N}_{2}$ и $\mathrm{O}_{2}$ ) его содержится $11,2 \%$, а в газе вращаюшихся реторт даже $17,0 \%$ (табл. 3 ).

Характерная особенность сланца - при относительно невысоких температурах разлагаться с выделением водорода - обусловливает более низкую концентрацию углеводородов.

При циркуляции парогазовой омеси по системе перегревателей в туннельных печах разложению может подвергаться в известной мере и часть паров смолы. При этом относительное количество углеводородов в газе увеличивается, тем самым снижается концентрация водорода и других компонентов, хотя в абсолютном значении выход водорода из сланца в туннельной печи больше, чем во вращающейся реторте.

Во вращающейся реторте парогазовая смесь эвакуируется из горячей зоны значительно быстрее, чем это происходит в туннельной печи. Ввиду этого в ней исключено дальнейшее разложение смолы и газа.

Выход газа в туннельной печи составляет на сланец 4,5\% весовых, тогда как во вращающейся реторте $2,5 \%$, что составляет на 1 т рабочето сланца (при удельном весе газа $1,5 \mathrm{kr} / \mathrm{Hм}^{3} *$ ), соответственно, $23 \mathrm{Hм}^{3} / \mathrm{T}$ и $17 \mathrm{Hм}^{3} / \mathrm{T}$ (табл. 3) **.

При сравнении газов крекинга нефти и полукоксования кукерскогс сланца с целью определения возможности более рационального применения последнего, можно отметить следующее.

1. Сланцевый полукоксовый газ обычно на одну треть состоит из балласта $\mathrm{CO}_{2}+\mathrm{H}_{2} \mathrm{~S}$.

2. Неуглеводородные горючие компоненты $\mathrm{CO}+\mathrm{H}_{2}$ в нем составляют величину порядка $10-15 \%$ (объемных).

3. Действующая технология переработки горючих сланцев связана со значительными подсосами воздуха, вследствие чего трудноустраняемый балласт $\mathrm{N}_{2}+\mathrm{O}_{2}$ в сланцевом полукоксовом газе составляет значительную величину $(20-50 \%)$.

Все эти обстоятельства снижают концентрацию ценных углеводородных компонентов в сланцевом газе, по сравнению с нефтяным газом.

4. Фракция $\mathrm{C}_{4}$ полукоксового сланцевого газа в значительной части состоит из бутан-бутиленовой смеси нормального строения.

На состав газа может оказывать влияние также величина кусков перерабатываемого сланца; однако специальных исследований по этому вопросу еще нет. Туннельные печи используют лишь тщательно отсортированный от мелочи кусковой сланец, тогда как вращающаяся реторта перерабатывает вместе с кусковым сланцем также и сланцевую мелочь.

* Из-за подсосов воздуха в систему печей газ сильно разбавлен азотом, ввиду чего фактически его удельный вес составляет $1,3 \mathrm{kr} / \mathrm{Hм}^{3}$.

** Содержание органического вещества в технологическом сланце туннельных печей составляет $31-32 \%$, в технологическом сланце вращающейся реторты - $35-36 \%$. 


\section{Возможные пути использования углеводородной части сланцевого газа}

В практике нефтеперерабатывающей промышленности для химической переработки используется обычно не весь газ, а фракции, наиболее богатые непредельными углеводородами.

Целесообразно поэтому проследить выход отдельных углеводородных компонентов исходя из перерабатываемой в туннельной печи одной тысячи тонн рабочего сланца с влажностью $10 \%$ и содержанием органической части $30-32 \%$.

Выход газа (за вычетом $\mathrm{N}_{2}+\mathrm{O}_{2}$ ), в количестве $4,2 \%$ от сланца, может составить 26400 нм³ $^{3}$.

Соответственно этому, выход отдельных компонентов непредельного ряда составит:

$$
\begin{aligned}
& \mathrm{C}_{2} \mathrm{H}_{4} \ldots 1270 \text { нм}^{3} \text {, или } 1600 \text { кг } \\
& \mathrm{C}_{3} \mathrm{H}_{6} \ldots 1670 \text {, , } 3100 \text {, }
\end{aligned}
$$

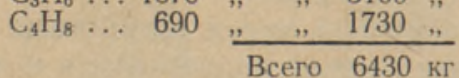

Пропиленовая фракция при этом является преобладающей, поэтому при химическом использовании полукоксового сланцевого газа более всего следует ориентироваться на эту часть газа.

Наличие в газе больших количеств этана и пропана, (соответственно, 4200 и $3800 \mathrm{kr} / 1000 \mathrm{~m}^{3}$ ) позволяет проводить отдельно крекинг газовой смеси с получением дополнительных ресурсов этилена и пропилена. В результате их дальнейшей переработки можно получить либо химические продукты, либо высокооктановое моторное топливо.

Имеется еще одна возможность, которая напрашивается при использовании сланцевого полукоксового газа, - получение жидкого газа $\left({ }^{6}\right)$,

Подсчет выходов отдельных углеводородных компонентов на 1000 т

\begin{tabular}{|c|c|c|c|c|}
\hline $\begin{array}{l}\mathrm{CH} \\
\mathrm{C}_{2} \mathrm{H}_{6} \\
\mathrm{C}_{3} \mathrm{H}_{8} \\
\mathrm{C}_{4} \mathrm{H}_{10}\end{array}$ & $\begin{array}{r}3430 \\
3160 \\
1720 \\
\quad \quad 475\end{array}$ & $\begin{array}{c}\text { Hм }^{3} \\
", \\
",\end{array}$ & илг & $\begin{array}{l}2460 \mathrm{k} \\
4260 \\
3780 \\
1260\end{array}$ \\
\hline
\end{tabular}
сланца показывает, что на предельную часть приходится:

Bcero $11760 \mathrm{Kr}$

Bсего, таким образом, вместе с непредельной частью из 1000 т сланца получается 18,2 т углеводородов. Более половины этого количества приходится на фракции $\mathrm{C}_{3}$ и $\mathrm{C}_{4}$, составляющие в общей смеси $9,8 \mathrm{~T}$.

Эту часть можно использовать в качестве жидкого газа для бытовых и технических целей.

Сжиженная газовая смесь с таким составом является оптимальной для указанных целей, так как она более чем на две трети будет состоять из фракций $\mathrm{C}_{3}$. Это обстоятельство сможет обеспечить жидкому сланцевому газу пребуемое предельное давление как в зимних, так и в летних условиях.

Оставшаяся неконденсированная часть газа, содержащая $\mathrm{CH}_{4}, \mathrm{C}_{2} \mathrm{H}_{6}$ и другие компоненты, имеет теплотворную способность свыше 4000 ккал/нм³ и может быть использована на месте как бытовой или энергетический газ.

В настоящее время жидкий газ приобретает все большее значение в качество бытового топлива, а также в автотранспорте. Он получается преимущественно на базе добычи и переработки нефти. Сланцевый полукоксовый газ, как видно из вышеизложенного, имеет в своем составе 
достаточное количество легкоконденсирующихся углеводородных компонентов $\mathrm{C}_{3}$ и $\mathrm{C}_{4}$, необходимых для производства жидкого газа.

Жидким газом можно снабжать окраины городов, где жилые постройки разбросаны на большой площади, а также отдельные поселки и населенные пункты, куда проведение газопровода считается нерациональным.

\section{Выводы}

1. Сланцевый лолукоксовый газ характеризуется высокой кконцентрацией кислых компонентов $\mathrm{CO}_{2}+\mathrm{H}_{2} \mathrm{~S}$, образующихся главным образом в начальной стадии разложения органической части сланца.

2. Углеводородная часть от $\mathrm{C}_{1}$ до $\mathrm{C}_{4}$ составляет около $35-40 \%$ газа (по объему), при этом до $30 \%$ ее приходится на углеводороды непредельного ряда.

3. Наибольший выход (по весу) имеют фракции этана, пропана и пропилена. Фракция $\mathrm{C}_{2}$ на $75 \%$ состоит из этана.

4. По характеру углеводородной части газ полукоксования сланца сходен с газом крекинга нефти. Кривая степени ненасыщенности у полукоксового сланцевого газа по сравнению с нефтяным газом проходит между кривыми продуктов жидкофазного и парофазного крекинга.

5. Относительно высокое содержание в газе фракции $\mathrm{C}_{3}$ позволяет использовать газ полукоксования сланцев для производства жидкого газа.
Институт. химии
Академии наук Эстонской ССР
Поступила в редакцию 15 IV 1954

\section{ЛИТЕРАТУРА}

1. М. И. Дементьев а, Анализ углеводородных газов, Гостоптехнздат, 1951.

2. А. Ф. Добрян ский, Горючие сланцы СССР, Гостоптехиздат, 1951.

3. П. К. Коге р м ан, Химия эстонских сланцев, Госхимтехиздат, 1934.

4. И. П. Нихамов и. В. П. Цыб а сов, Предварительные данные по исследованию гдовских сланцев, «Горючие сланцы» № 3, 1933.

5. H. Raudsep p, Pőlevkivi uttegaasid keemiatööstuse toorainena, „Tehnika ajakiri”, nr. $9 / 10,1940$.

6. А. Р ом ен и Д ж. К р а п п е, Справочник по бутан-пропану, Гостоптехнздат, 1949.

7. С. Р. С ергиенко, Химическое использование природных и промышленных газов, изд. АН УССР, 1951. 